\title{
Explaining Masks Disobedience Difference in the U.S. at the Beginning of COVID-19: Material, Competence, Meaning
}

\author{
Beiqi Zhang ${ }^{1, a,{ }^{*} \dagger}$, Qiming Liu ${ }^{2, b,{ }^{*} \dagger}$ \\ ${ }^{1}$ School of Ethnology and Sociology, Minzu University of China, Beijing, China \\ ${ }^{2}$ Catholic Memorial School, West Roxbury, Massachusetts, United States \\ ${ }^{*}$ Corresponding author.Email: ${ }^{a} 19010897 @ m u c . e d u . c n,{ }^{b}$ Qimingliu@catholicmemorial.org \\ These authors contributed equally.
}

\begin{abstract}
Marks play an important role in every pandemic since they have shown up in human history. However, at the beginning of the COVID-19, U.S. failed to apply the wearing masks policy in time. The lack of using masks led to the spread of COVID-19 and the dramatic death numbers. To explain the unexpected situation, it is necessary to analyse the status of masks on three-dimension elements: material, competence, and meaning. This three-dimension elements analysis comes from practical theory, a realm that is appropriate and comprehensive for delineating the repercussion of lack of mask. It breaks down the dualism thought in social discussion. Besides, the perspective of practice theory reorganizes the logic of individual actors, compensating the disadvantage of the original theory. The practice theory is ground-breaking because it uses ordered social practice across space and time instead of the experience of individual actors and social totality. It breaks down the dualism thought in social discussion, setting the foundation of theory on the assumption that practice from agency and structure. This research collects statistics from the famous, wide, complete online forum Quora. This platform ensures the wideness of the information, accepting opinions from the whole American area and the whole world. By enlisting accurate and concrete information, this article will unveil the origin of the difference in mask habits and the deep reasons behind the ethical reasons of the gap between the infection rate and casualties between different ethnic groups. The theory author proposed in this article is based on authentic data, obeying the data saturation rule. The method of collecting data ensures the authenticity of information and declines the subjectivity in the analysis. This research will contribute to society by creating more background studying for the disease history study and reducing the unnecessary death caused by bad habits.
\end{abstract}

Keywords: the U.S., COVID-19, Theory of Practice, Three Elements of Practices: Material, Competence, Meaning, Masks habits.

\section{INTRODUCTION}

Discriminations and criticisms have been raised against Asian under the breakout of COVID-19, an uncontrollable event, in China, Asia, 2019. With the surge of the total infection number in the United States in the early period of COVID-19, a gap appears between Asian American and other ethnic groups due to Asian unique behaviour pattern. The unrightful discrimination and criticism motivate Asians to speak for themselves and justifies their social appearance. Besides, the surprising difference in infection rate and the unexpected significant repercussion of COVID-19 and coerces people to rethink the ways Asian Americans exist in
American society and the directions Other ethnic groups should remedy.

\subsection{COVID-19}

COVID-19 is a rife contiguous respiratory disease. It was caused by severe acute respiratory syndrome coronavirus (SARS-Cov-2). WHO informed this virus from China for the first time in December, 2019. Meanwhile, the virus then readily spread to the whole China. Additionally, it became a global pandemic due to the highly developed modern transportation. All of these happen under the backdrop of the widest epidemic in human history, COVID-19. On Jan. $11^{\text {th }}$, the first 
COVID-19 death appeared in China; on Jan. $20^{\text {th }}$, the first confirmed case outside mainland China was found in Japan; on Jan. $21^{\text {st }}$, the first case on the United States was reported; on Jan. $30^{\text {th }}, 2020$, W.H.O declared a global health emergency; on Feb. $2^{\text {nd }}, 2$ 2020, the first COVID-19 death outside China happened in the Philippines [1]. The world suffered from this pandemic, where American is the center of the pandemic.

\subsection{COVID-19 impact on the United States}

The United States is one of the countries that were affected by the pandemic the most. On March 26, 2020, United States officially became the most serious hit country: at least 81,321 confirmed infections and more than 1,000 deaths, more cases than in China or any other country at the time [1]. Since then, America has maintained its leading place of confirmed cases. On February $22^{\text {nd }}, 2021$, the U.S. News claimed, 'The COVID-19 death toll in the U.S. has topped 500,000, all but matching the number of Americans killed in World War II, Korea, and Vietnam combined' [2]. In the United States only, the number of unemployed people raised by 25 million, and the size of the labor force contracted by more than 8 million [3]. The regression of economic also leads to worsening of the society and indirectly causes more cases and death. The more severe the impact of COVID-19 is to Americans, the more people should be serious about the gap of infection rate between races.

\subsection{Masks disobedience in the U.S.}

Asian shows a phenomenal difference than on infection case than other ethnic groups. In 2021, the infection of COVID-19 of non-Hispanic white is $50.1 \%$, that of Hispanic is $28.8 \%$, and that of Black is $11.3 \%$. However, that of Asian is only 3.2\%. [4] and the death rate of Asian reaches 3.9\%.[5]

During COVID-19, difference age, racial, and local group in American presented a different masks habit. By age, American teenager presented a much worse masks strategy than people from other ages. During the very beginning of COVID-19, a lot of the American teenagers, due to the close of school, gathered for party without masks. They also gathered on the beaches and other places with no facial covering material. The fearless and ridiculous actions was partial a result of low death rate. According to research, the death rate of American teenagers who was infected was lower than the chance of being hit by a truck in 10 years. The infection rate of the white teenagers is significantly high although the death rate is pretty low.

Wearing no masks and being infected for American teens was only a chance to be 'vaccinated' by the virus. This attitude prevented the civil education of masks habit to the American teens.
Based on racial, Asian American presented a better masks strategy than other ethnic groups. Asian American in United occupies is a special place. They account for $5.7 \%$ of the national population [6]. They have an average income of $\$ 98,174$ per year in 2019 , highest in all the race [7]. The only explanation of this inconsistency is that Asian American has a higher middle-class rate but less dominance economic force. Asian Americans also have a lower political attendance rate. In the 117th U.S. Congress, only 19 of 439 house members are Asian American and only 2 of 100 senate members are Asian American [8]. While Americans often encounter the Black civil rights campaign, there is seldom an Asian civil rights campaign in America. Moreover, this stable status of the Asian American leads to less participation of the politic and more obedience to the government.

Asian Americans are new immigrants comparing to white, Hispanic, and black. The first real lawful AsianAmerican no existed until 1943 [9]. They remain more connected to their mother countries. Hence, the historically empirical knowledge, e.g., how to treat pneumonia, can be passed to the close generation. They also maintain the ways they used to educate in the civil education dimension and some parts of their practical social habits. These qualities of Asian Americans make them different in the pandemic.

As for local area, states like California and Florida have a much worse masks habits in total and a much higher infection rate of coronavirus. By law, the states have right to arrange their own policies about the COVID-19 and masks by themselves separately. Comparing to the big states with dense population and active economy, Massachusetts has smaller population and rather old economy. This state has strict law on COVID-19 and masks, because it will be easy to enforce and have less damage to economy. Whereas in New York, an area near Massachusetts, the masks policies are entirely different. New York's population is much denser than Massachusetts and its economy requests for much more circulation of people. The severe masks policies do not work readily here. Besides, New York has had and kept having the most dangerous situation in the beginning of COVID-19 period.

The essay is divided into several sections. After this background section, the essay will present the theory. Then, it will show the method and data. Subsequently, the essay will analyze the collected data according to the theory. The concluding words will shed light on further studies. 


\section{THEORY OF PRACTICE: PRACTICE AND ELEMENTS}

Giddens suggests that the basic domain of study of the social sciences is social practices ordered across space and time [10]. Locating practices as the primary of analysis could transcend the dualisms of structure and agency, determination and voluntarism. In this way, the practice-as-an-entity exists and is reproduced by successive spots of performance, and individuals are seen as practitioners, the carriers of a practice [11]. Wearing face masks is a kind of practice, which can be analyzed employing practice theory. We will first present the theory, then will discuss the three elements of practices.

According to Blue, the theory of practice is established and developed based on Giddens, Bourdieu, Foucault, Heidegger, Wittgenstein, and Marx, amongst others [12]. Shove is one of the representatives of practical theory, who developed the theory of practice based on the former theories.

The theory of practice has two basic propositions. According to Elizabeth shove, 'the first is that social practices consist of elements that are integrated when practices are enacted. The second is that practices emerge, persist, and disappear as links between their defining elements are made and broken' [11].

The concept of elements of which practices are composed comes from Reckwitz. Reckwitz reveals that practices are made up of 'forms of bodily activities, forms of mental activities, things and their use, a background knowledge in the form of understanding, know-how, states of emotion and motivational knowledge' [13]. Based on Reckwitz's work, Shove simplify them to three elements: marital, competence, and meaning.

Material, in Shove's words, encompass 'objects, infrastructures, tools, hardware and the body itself' [11]. The face mask itself is a kind of material. As an element of practice, the characteristics of the mask, such as the price or quantity of face masks, will affect masking.

Competence is a complicated element, including know-how, background knowledge, and understanding. To be more precise, competence consists of two kinds of knowledge. One is 'knowing in the sense of being able to evaluate performance, the other is knowing in the sense of having the skills required to perform' [14]. Maskrelated competencies include understanding the ability of the mask to prevent droplet transmission and knowing how to choose effective face masks in a disease situation.

Meaning covers' mental activities, emotion and motivational knowledge' [11]. It should be noted that meaning is an internal integrant rather than an extrinsic driving force. There may be some different meanings being the element of masking in the flow of time.
The three elements of practice and their interdependencies vary at different time points. Shove indicates in theory that the development of practice could be represented through a serious of snapshots with materials, meanings, and competencies involved at different moments [11]. In implication, changes in masking could be analyzed by comparing elements involved in different snapshots. An important point in the comparison is that theory of practice assumes that elements will not be obliterated or dissolved but instead overlain [11].

Multiple practices are also linked because of elements. Two practices that have a common element can be linked by this point of connection, but often the connection is unstable. This link is likely to break as the other peculiar elements develop.

We will apply this idea to analyze the changes in wearing masks. By looking at changes in the elements of mask-wearing and its relation to other practices, we explore the reason why masking falters and thrives.

\section{DATA AND METHOD}

\subsection{Data}

This article utilizes data from the American internet forum Quora. Choosing an internet forum as data results have the following advantages. First, netizens have a strong heterogeneity; different classes, races, educational levels, etc. can be seen on the internet. This different social status netizens' speech can form a rather complete group of public speech. Moreover, a forum on the internet can represent the real thoughts of the citizens. Under the big circumstance of seeking political correctness, the pressure people receive from the online forum will be smaller than that from reality.

Additionally, choosing Quora is crucial because it is a public, large-scale, and populous American online forum. It is also a 'question-and-answer website' and will classify organically the question in one field, which is beneficial to the convergence, communication, and reservation of opinions. Quora's focus forthwith on a societal topic. Following the attention and clicks of a topic, this topic will attract continuous discussion.

Considering the morality problem, this article quotes Quora users anonymously. For the sake of prevention of leak of users' personal information, this article will use an anonymous process utilizing the first letter of their last username.

In the collection of data source, this article obeys the Data saturation rule: 'Data saturation refers to the point in the research process when no new information is discovered in data analysis and this redundancy signals to researchers that data collection may cease ' [15] 


\subsection{Method}

This research adopts the following step on literature analysis:

step 1. use keyword search 'Quora US wear masks.

step 2. go to Quora, follow a relevant question and read answers.

step 3. keep a record of relevant answers and summarise with keywords (codes)

step 4. classify codes into explanatory strands about meaning-making.

On step 2, the source for the topic "Why are Americans so resistant to masks?" is collected from June $5^{\text {th }}, 2021$, to June $11^{\mathrm{h}} 2021 .[16]$

This research method can code the information based on enough information, distinguishing and classifying the information on a conception level, and integrating them to unearth the deep meaning behind the text. The coding rule of the research is stated as following. According to the time sequence of collecting the data, we will use number as the first blank of the code. Then the first letter of username is used as the second and a third of the code. Finally, due to a user can have different opinion, this article will use lower case letter to represent different answers from the same user.

Nonetheless, this method has a certain restriction. For example, the process of the information cannot fully ignore the subjectivity of the researchers. Moreover, netizens' opinions often have the characteristics of highly fluctuated. An online forum can also delete some of the sensitive speeches.

\section{ANALYSIS}

The research result is presented in Table 1 as follows.

Table 1. Coding Results

\begin{tabular}{|c|c|c|}
\hline level & $\begin{array}{l}\text { explanatory } \\
\text { strand }\end{array}$ & code \\
\hline \multirow{4}{*}{$\begin{array}{l}\text { Competence } \\
\text { Level }\end{array}$} & \multirow{4}{*}{ Ignorance } & $\begin{array}{l}\text { 1RPa: analogy of COVID-19 } \\
\text { to flu }\end{array}$ \\
\hline & & 2DTa: hoax perception \\
\hline & & 6JSa: don't work \\
\hline & & 1RPb: political signifier \\
\hline \multirow{4}{*}{$\begin{array}{l}\text { Meaning } \\
\text { Level }\end{array}$} & \multirow{4}{*}{ Freedom } & 1RPc: government control \\
\hline & & 2DTb: government oppression \\
\hline & & 3PSa: freedom \\
\hline & & 5MGa: rights \\
\hline
\end{tabular}

\begin{tabular}{|c|c|c|}
\hline & & 4TPb: political leadership \\
\hline & & 4TPa: cultural arrogance \\
\hline & & 3PSb: individuality \\
\hline & & 7KCa: take risks. \\
\hline & & 8EMa: individuality \\
\hline & & 9RRa: political leadership \\
\hline & & 10JHa: political leadership \\
\hline $\begin{array}{l}\text { Material } \\
\text { Level }\end{array}$ & Mask & 8EMb: uncomfortable \\
\hline
\end{tabular}

\subsection{Material level}

According to Table 1, some Americans refuse to wear masks due to the reason on the material level。

The material dimension is essential. As a result of the limitation on exhaling and inhaling, masks will make some people feel hard to breathe. Apart from that, in lowtemperature areas, due to the design of masks, exhaled air will cause fog on the glasses, influencing the eyesight of people. And in high-temperature areas, masks will also accumulate heat to some degree, the material properties of masks form a threshold for some people who cannot afford the difficulty caused by masks to wear masks.

\subsection{Ignorance, competence level}

On the dimension of competence level, Americans have an ignorance of the background knowledge of wearing a mask as a practice. First of all, wearing the mask as a practice is fulfilled under the background of COVID-19, masks and COVID-19 already linked deeply. When people talk about wearing masks, the answer often gives their response using COVID-19 context. There are two factors about the competence of wearing masks: COVID-19 and the little harm masks themselves will do to Americans. They treat COVID-19 as other flu, thinking that COVID-19 is not harmful enough to let Americans treat it seriously. Some people even use the perspective of conspiracy theory to understand COVID19 , regarding it as another hoax. To the understanding of masks, the people who do not wear masks do not think that masks will have any capability to prevent COVID19. The people who hold this opinion will have a backsight effect: using evidence after the event has taken place to support their theory, reinforcing the opinion of masks are useless. For instance, the school instead of asking students to wear masks as proof of masks is useless. Nevertheless, some people even connect wearing masks to the election, claiming the COVID-19 is only a lie for precluding Trump from winning the election. Moreover, wearing masks just another political symbol of the left. Above all, to an ability degree, not wearing 
masks is an ignorance of the danger of COVID-19 and mistrust of the usage of masks.

\subsection{Authority and freedom, meaning level}

On the dimension of meaning, wearing masks is seen as the opposite side of individual freedom. Masks become a medium of the conflict of individual rights and government power. Besides, it reflects the opposition of authority. Government requestions for masks make wearing masks an enforced practice; "authority" as a meaning embedded in the practice of wearing masks makes wearing masks undergoes a lot of resistance. Plenty of users on the forum mention that wearing a mask is an embodiment of government control and government oppression. In fact, choosing whether one person should wear masks is the liberty of an individual, containing other meaning of right, e.g., freedom of individuality. Some responders state that they cannot recognize each other anymore after they wear masks. Additionally, this kills the characteristics of a person, which should be "terrible" as an act. Moreover, the freedom of people who have a more robust body is also being restricted. For example, if someone feels like they have better immunity, they can choose to not wear masks. In conclusion, the practice of people does not wear masks is because authority is embedded into the practice of wearing masks under the background of COVID-19. This type of authority conflicts with the understanding of right and freedom is built in the past.

\section{CONCLUSION}

In summary, the essay has introduced the development of COVID-19 in the United States and its impact. In addition, the role of masks in the epidemic was discussed. Subsequently, it has demonstrated the three elements of practices from the perspective of a practice theory - material, competence, and meaning. Afterward, it has analysed the reasons why a significant portion of Americans are so resistant to face masks during the wave of COVID-19. As for material, the design of the masks can cause discomfort to the wearer. The discomfort can be even more acute for people who have trouble breathing themselves, as well as those who wear glasses. In addition, the essay has discovered competence matters. Wearing face masks requires people to be aware of their effects. Nevertheless, anti-maskers fail to grasp the seriousness of COVID-19 and unrecognize the role of masks in the containment of COVID-19. Besides, wearing masks is seen as an area of personal freedom versus government power in the meaning level. The boycott of masks is seen as a defence of freedom and rights.

This study not only deepens the understanding of the resistance to face masks in the United States but also helps understand its future tendency. Based on these understandings, more appropriate and targeted interventions can be taken to save more lives.

The essay has several limitations. The analysis may be incomplete and the evidence could be stronger and more diverse, e.g., quantitative data providing a general picture and observations of the actual situation.

Future research could focus on comparisons across time to see why some people persist in their resistance to masks while others do not. Furthermore, to fully understand the phenomenon, it is worthwhile to explore other perspectives and reasons.

\section{REFERENCES}

[1] A Timeline of the Coronavirus Pandemic, Derrick Bryson Taylor, March 17, 202, https://www.nytimes.com/article/coronavirustimeline.html

[2] The US Tops 500,000 Virus Deaths, Matching the Toll of 3 Wars, Associated Press, Feb. 22, 2021, https://www.usnews.com/news/healthnews/articles/2021-02-22/vaccine-effortsredoubled-as-us-death-toll-draws-near500k\#: :text=The $\% 20$ COVID $\% 2 D 19 \% 20$ death $\% 2$ 0toll,II\%2C\%20Korea\%20and\%20Vietnam $\% 20$ co mbined.

[3] Interim Economic Projections for 2020 and 2021, Congressional Budget Office, May 19th, 2020, https://www.cbo.gov/publication/56351

[4] Distribution of coronavirus (COVID-19) cases in the United States as of May 30, 2021, by ethnicity, John Elflein, Statista, Jun 1, 2021, https://www.statista.com/statistics/1122384/corona virus-covid19-cases-by-ethnicity-us/

[5] Distribution of COVID-19 (coronavirus disease) deaths in the United States as of May 26, 2021, by race, by John Elflein, Statista, Jun 1, 2021, https://www.statista.com/statistics/1122369/coviddeaths-distribution-by-race-us/

[6] OMH Home $>$ Policy and Data $>$ Minority Population Profiles $>$ Asian American

Profile: Asian Americans, U.S. Department of Health and Human Service Office of Minority Health, 4/5/2021, https://minorityhealth.hhs.gov/omh/browse.aspx?lv $\mathrm{l}=3$ \&lvlid $=63$

[7] Racial disparities in income and poverty remain largely unchanged amid strong income growth in 2019, Valerie Wilson, 09/16/2020, Economic Policy Institute, https://www.epi.org/blog/racialdisparities-in-income-and-poverty-remain-largelyunchanged-amid-strong-income-growth-in-2019/ 
[8] How Diverse is U.S. Congress?, Katharina Buchholz, Statista, Jan 2021, https:/www.statista.com/chart/18905/us-congressby-race-ethnicity/

[9] Timeline of Chinese Immigration to the United States, The Bancroft Library, University of California Regent, June 10, 2021, https://bancroft.berkeley.edu/collections/chineseimmigration-to-the-united-states-18841944/timeline.html

[10] Anthony Giddens, 1984. The constitution of society. Polity Press.

[11] Elizabeth Shove, Mika Pantzar, and Matt Watson, 2012. The Dynamics of Social Practice: Everyday Life and How It Changes. Sage.

[12] Stanley Blue, Elizabeth Shove, Chris Carmona \& Michael P. Kelly, 2014. Theories of practice and public health: understanding (un)healthy practices. Retrieved

from: https://www.tandfonline.com/doi/full/10.1080/095 81596.2014.980396.

[13] Andreas Reckwitz, 2002. Towards a theory of social practices: A development in culturalist theorizing. Retrieved from: https:/www.scirp.org/reference/referencespapers.a spx?referenceid $=2902456$

[14] Alan Warde, 2005. Consumption and theories of practice. Retrieved from: https://link.springer.com/chapter/10.1057/978-1137-55682-0 5

[15] Kostas Mouratidis, Victoria Cobeña Serrano, Autonomous buses: Intentions to use, passenger experiences, and suggestions for improvement, Transportation Research Part F: Traffic Psychology and Behaviour, 10.1016/j.trf.2020.12.007, 76, (321335), (2021). Retrieved from: https:/onlinelibrary.wiley.com/doi/abs/10.1002/97 81118901731. iecrm0060

[16] Quora.com. Retrieved from: https://www.quora.com/Why-are-Americans-soresistant-to-masks 